\title{
An Exploration and Extension of the Value Discipline Strategy (VDS) Typology in Educational Institutions
}

\subsection{Introduction}

The critical impact of strategy on the operation and performance of organizations is well established (Hambrick 1980). Following an initial focus on marketing strategy associated with physical goods (Lusch and Vargo, 2008, Hooley and Greenley, 2005) over the past 30 years, research in the area of services marketing strategy has gained momentum (Lovelock, 1983, Zeithaml et al., 1985, Gronroos, 1991). This area continues to be of considerable interest to researchers (Decaudin and Lacoste 2010; Zahay and Griffin 2010; Godlevskaja et al. 2011). Due to the divergent nature of service offerings, having a 'one size fits all' strategy is neither informative nor realistic, thus, the call for contextual specific research in the services domain is on the rise (Ostrom et al. 2010; Demirkan et al. 2008). One such service context that has received little attention in the marketing literature is within the education sector, in particular, the area of international student recruitment (ISR). This is a significant oversight given that the international education industry has become an important contributor to the global economy (e.g. Infometrics 2006; Association of International Educators 2007), with many countries now entering the international educational market (Bennell and Pearce 2003). Consequently, growth and competition now strongly characterize the international education market arena.

Historically, Kotler and Murphy (1981) called for the development of marketing strategy within the university sector. To some extent, this call was heard with the result that some marketing activities were implemented and then, later investigated. For example, Naude and Ivy (1999) investigated marketing tactics in UK universities while Marine and Foskett (2002) 
undertook some investigation of educational marketing strategies. However, the development of marketing strategies in the education sector was not universal. Mazzarol and Hosie (1996) report a lack of consistency in Australian international education marketing strategy while Maringe (2004) calls for the adoption of marketing practices by university managers in developing countries. However, the development of education marketing strategy research has tended to focus on the demand side (i.e., student choice, student perception) rather than a provider perspective (Ross et al. 2007). Although the idea of an international education market is now well established, education marketing knowledge is still under-developed (Hemsley-Brown and Oplatka 2006; 2010).

This study, therefore, addresses this deficit by adopting the Value Discipline Strategy (VDS) typology (Treacy and Wiersema 1995) as an appropriate framework upon which to investigate and expand our knowledge of ISR strategies operating in educational institutions. Through our empirical results, we provide an extension to the VDS typology using a methodological approach (i.e. self-typing paragraph method) previously used for strategy identification, however, not in relation to the VDS typology. On this basis, the contribution of the research is threefold. Firstly, we extend marketing strategy theory through the expanded VDS model. Secondly, we identify and validate strategies adopted by ISR departments across two countries and, finally, we validate the use of the self-typing paragraph method as an appropriate mechanism for strategy identification. In doing so, significant theoretical and practical implications are provided and a solid framework for future research is established.

\subsection{Marketing Typology Strategies}


Two of the most dominant strategy frameworks are the typologies developed by Miles and Snow (1978) and Porter (1980) (Slater and Olson 2001). The Miles and Snow (1978) typology focuses on three types of strategic problems: entrepreneurial, engineering and administrative, as the indicators of an organization's strategy (Conant et al. 1990; Slater et al. 2006). On this basis, the extent to which the organization actively engages in market scanning determines whether they are prospectors, defenders, analysers or reactors (Bednall and Valos 2005; Hooley et al. 1992). Of these four, reactors are found to exist when one of the other strategies is inconsistently applied by the organization (Slater and Narver 1993).

Porter (1985), on the other hand, proposes that strategy is an action that is deliberately undertaken (Walker and Ruekert 1987) to achieve competitive advantage and long-term business growth. He proposes cost leadership and differentiation as strategies with industrywide targets and focus as a strategy with a specific target. Porter (1985) argues that in trying to achieve competitive advantage, organizations may employ a cost leadership strategy when price leadership is their goal, a differentiation strategy when attempting to achieve competitive advantage through uniqueness, and a focus strategy existing when organizations concentrate on the development of a niche market. However, in line with the Miles and Snow's (1978) reactor strategy, Porter (1985) considers organizations that fail to develop one of the three strategies to be stuck in the middle.

Both Miles and Snow (1978) and Porter (1985) emphasise market growth in their strategy typologies. Miles and Snow (1978) consider growth from product market change while Porter (1985) concentrates on growth through competitive actions (Walker and Ruekert 1987). While market growth may be particularly important for many for-profit organizations, this is not always the case for not-for-profit organizations such as educational institutions. 
For example, when recruiting international students, some educational institutions simply seek to maintain the overall number of international students attending their institution from year to year. In a growing market, such as international education (UNESCO 2009), merely maintaining the number of international students actually equates to negative growth in real terms. Additionally, some educational institutions enrol international students for reasons such as developing a diverse student body or facilitating personal growth. For these institutions, growth, market share and profit are not determinants of their ISR marketing strategy. Therefore, institutions evaluated on the basis of growth as the performance indicator, may well perform quite poorly despite the fact that their ISR objectives have successfully achieved. On this basis, it could be argued that the strategy typologies of Porter (1985) and Miles and Snow (1978), do not have their focus in an area that can be applied meaningfully to ISR.

\section{Value Disciplines Strategy (VDS)}

In contrast to the abovementioned typologies, Treacy and Wiersema (1995) propose a classification of marketing strategies based around value. Known as the Value Disciplines; operational excellence, customer intimacy and product leadership are strategies articulated in order for organizations to seek out superior value for their customers. Operational excellence exemplifies the organization focussing on the provision of value through the best total cost for a service, with an emphasis on quality, price and the delivery systems. Organizations adopting a customer intimacy strategy emphasise the provision of value through developing relationships and offering the best total solution for a consumer. Product leadership, on the other hand, is adopted by organizations that provide value by developing the best product or service. 
The VDS (Treacy and Wiersema 1995) have been used in a wide range of contexts both conceptual and empirical. Within the conceptual literature, the VDS have been used in areas such as knowledge management (Wiig, 1997), human resource management (Schuler, 1996), customer value (Christopher, 1996), customer relationship management (Langerak and Verhoef, 2008), strategy mapping (Scholey, 2005) and educational service encounters (Chung and McLarney, 2000). Empirical studies have used the VDS in areas such as knowledge management and organisational performance (Zack et al., 2009), market orientation (Micheels and Gow, 2009), Web 2.0 strategies (Wijaya et al., 2011), customer preferences (Dannhauser and Roodt, 2001), the development of strategic advantage (Bendoly et al., 2009), and strategic purity (Thornhill and White, 2007).

Given that the VDS typology developed by Treacy and Wiersema (1995) does not hold its focus around financial performance outcomes such as market growth and profitability, but rather gravitates around the creation of value for customers and organizations, this is a more appropriate framework to help us understand ISR strategies of educational institutions. In fact, the perceived commercialisation of education has resulted in a degree of academic scepticism towards education marketing on the basis of profitability (Harvey and Busher 1996; Naidoo 2010). For organizations, such as educational institutions, that recruit international students for other reasons than profit, an examination of marketing strategies in ISR using the VDS typology may well be more appropriate, informative and appealing to academic practitioners. On this basis, we propose the following research question:

RQ1: ISR marketing strategies used by educational institutions can be identified in accordance with a value-based strategy typology. 
To further our exploration of marketing strategy in educational institutions, it is important to determine if the VDS is an appropriate typology to identify marketing strategies of ISR departments across countries. It is expected that, where similarities lie between the educational objectives and systems of countries, the VDS model is expected to perform in a similar manner. For example, while located on opposite sides of the Tasman Sea, Australia and New Zealand are both Anglosphere nations (Bennett 2004). Both countries have a three tier education model (primary, secondary \& tertiary) which operates on the calendar year and the standard of education is comparable with both countries achieving very similar PISA ${ }^{1}$ results across all categories (OECD 2010). Given the similarities between these countries and education systems, it is expected that ISR marketing strategies evident in Australia and New Zealand will be of a similar nature. Thus, we pose the following question.

RQ2: To what degree are the prevailing ISR marketing strategies of Australia and New Zealand educational institutions similar?

In addition to exploring the similarities/differences of ISR strategies between countries, it is important to also acknowledge that ISR is important, not only to universities, but also to other educational entities. While the university sector is the largest and fastest growing of the international education sectors (UNESCO 2009) the secondary school sector (although a considerably smaller sector) has been described as largely undeveloped (Kenyon and Koshy 2003). Based on these sectoral differences, in relation to size and growth, it is anticipated

\footnotetext{
${ }^{1}$ The Programme for International Student Assessment (PISA) is an internationally standardised assessment that was jointly developed by participating economies and administered to 15-year-olds in schools. For further information about PISA refer to http://www.pisa.oecd.org/pages/0,3417,en_32252351_32235731_1_1_1_1_1,00.html
} 
that differences in the prevailing ISR marketing strategies across these sectors will also be evident.

RQ3: To what degree do the prevailing ISR marketing strategies of university and secondary school educational institutions differ?

\subsection{Methodology}

In order to address the research questions of this study, a two-phase research design was employed. Phase 1 involved depth-interviews with ISR marketing practitioners across educational sectors, while Phase 2 involved the use of an on-line survey to a larger sample of ISR marketing practitioners. Each phase is discussed accordingly.

\section{Phase 1 (Interviews): Method}

Ten depth-interviews were undertaken with ISR marketing practitioners from universities and secondary schools in Australia and New Zealand. Practitioners and educational institutions were selected as a representation of a broad range of institutions and a single informant was interviewed from each institution. In each case, the informant was actively involved in the development and implementation of the institution's ISR marketing strategy. This approach is similar to that justified in previous strategy research (Conant et al. 1990; Morgan et al. 2003) and the guidelines provided by Huber and Power (1985) were a major consideration when selecting key informants. As such, informants from three universities in Australia and three universities in New Zealand and two secondary schools in Australia and two secondary schools in New Zealand formed the respondent pool. 
The purpose of this preliminary stage to the research was to validate that the value discipline strategies were identifiable as relevant strategies in the context of the objectives of ISR departments within educational institutions. Furthermore, the interviews were largely unstructured to enable the emergence of new themes in the research context. On this basis, interviews were relatively unstructured whereby informants were encouraged to describe and comment, in their own words, on the strategies adopted within their respective departments.

\section{Phase 1 (Interviews): Results}

Data were gathered by the tape-recording of interviews which were, subsequently, transcribed and underwent a thematic analysis by three marketing academics. This is an established method of analysis (Howitt and Cramer, 2010) which involves the identification of themes emerging from the interviews and consensus, regarding the themes, being reached among the analysts. Each academic analysed the transcripts with the view to identifying the relevant strategies of interest and the categorisation of such using the VDS typology. The respective analyses were compared, discussed and consensus was reached between the academics in regards to the validation of the VDS typology and the emergence of new themes. Overwhelming the VDS typology of product leadership, customer intimacy and operational excellence were clearly identifiable within the data. While respondents were not asked directly to classify their departments as engaging in these strategies, they were asked to comment on the viability of such strategies in the ISR context and their associated experience with such strategies in their own departments or in the departments of other educational institutions.

In relation to the university informants, largely (but not exclusively) the themes centred around those associated with product leadership with reference to operational excellence also 
being evident in the data. Discussions evolving around customer intimacy were quite prevalent with secondary schools, however, only those operating in Australia. New Zealand secondary school informants' comments were large focussed around product leadership. While the interviews clearly provided evidence of the applicability of the VDS typology in the context ISR, they also highlighted this typology was incomplete. Table 1 provides a summary of strategy characteristics (along with associated informant comments) identified from the transcripts and this forms the basis for the proposal of a fourth strategy categorisation which we label as entrenched isolation.

\section{---- $\quad$ Place Table 1 about Here -----}

This strategy actively emphasises an entrenched method of operation, encourages the development of information and operational silos within the ISR departments and discourages external influences. Respondents' comments suggested that this was an active strategic process, not a reactive strategy (Miles and Snow 1978), the result of being stuck between strategies (Porter 1980; 1998) or a failure to adopt an international education strategy (Mazzarol and Soutar 2008). This strategy emphasises an active process of introversion and isolation, thus exemplified by its label entrenched isolation. Respondent's comments suggested that this strategy type was considered as a strategic objective and not as a barrier to achieving one of the VDS. Entrenched isolation is, therefore, defined as an internally focussed organizational marketing strategy perceived to create value for internal organisational stakeholders through knowledge gathering and retention within the silos of individual departments. Individual performance is paramount and synergies between silos are not actively sought to achieve marketing objectives. Maintaining control within individual silos is of the utmost importance and resistance to change is high, thus resulting in 
poor market adaptability. Due to its active internal focus, Entrenched Isolation impedes the creation of external value for the organisation.

In summary, Phase 1 resulted in the validation of the VDS typology as an appropriate and relevant mechanism to understand marketing strategies in ISR departments of educational institutions. In addition, a fourth strategy labelled as entrenched isolation emerged and which provides an extended framework for the research conducted in Phase 2.

\section{Phase 2 (Survey): Method}

The purpose of Phase 2 was to gather data from a larger, more generalizable, sample of ISR professions in educational institutions in order to empirically validate the proposed extended VDS model resulting from Phase 1. This phase involved the administration of a self-report on-line survey, the link to which was emailed to potential respondents. In the survey respondents were asked to read descriptions of ISR marketing strategy and then nominate which descriptor provided the most accurate description of the current strategy employed in their respective educational institutions. This method of data collection is referred to as the self typing paragraph approach which has been previously used and validated in strategy research (e.g., Conant et al. 1990; McKee et al. 1989; James and Hatten 1995; Shortell and Zajac 1990). The descriptions of the four ISR marketing strategies used in the survey instrument are shown in Table 2.

\section{---- $\quad$ Place Table 2 about Here}

The sampling frame was drawn from a database of email addresses of all ISR marketing practitioners in Australian and New Zealand education institutions. This was compiled by the 
researchers from government and institutions' websites. The survey link was emailed to the entire sampling frame, 1730 ISR professionals, and, to improve the response rate, follow-up emails were sent five days and ten days after the initial invitational email (Ilieva et al. 2002). The resultant sample of useable surveys was 504, representing a response rate of $29.1 \%$ (refer Table 3). Due to the anonymous nature of the survey, non-respondents were not identifiable. Therefore, to test for non-response bias we adopted an accepted proxy method of comparing late responses $(n=50)$ with early responders $(n=454)$ (Armstrong and Overton, 1977) via the use of means difference t-tests. No significant mean difference was detected, therefore, nonresponse bias in the data was deemed to be non-problematic. At institutions from which a usable response was attained, international student populations ranged from 2 to 12851 $(\mathrm{M}=1883$, mean=85) and comprised $.25 \%$ to $38.7 \%$ of total student populations $(\mathrm{M}=9.0 \%$, mean $=6.0 \%)$. Additionally, institutional ISR experience ranged from 1 to 57 years $(M=14.1$ years, mean $=13$ years).

\section{---- $\quad$ Place Table 3 about Here}

\section{Phase 2 (Survey): Results}

Results of the survey can be seen in Table 4. Overall an operational excellence ISR marketing strategy (34.3\%) was found to be most prevalent, followed by customer intimacy (31.3\%), entrenched Isolation (20.2\%) and, finally, product leadership (14.1\%). Although differences are apparent by sector, each ISR marketing strategy contains a mix of both schools and universities from both Australia and New Zealand. The most prevalent ISR marketing strategy for the school sector was customer Intimacy $(41.4 \%)$, whereas for the university sector operational excellence (47.3\%) was most prevalent. A cross country comparison shows customer intimacy to be most prevalent in both Australian and New 
Zealand schools while operational excellence is most prevalent in both Australian and New Zealand Universities.

\section{---- $\quad$ Place Table 4 about Here -----}

In summary, an extended version of the VDS typology was validated by the findings, thus addressing RQ1. In terms of RQ2, we found that there does appear to be significant similarities in the adopted marketing strategies of ISR departments across the two countries compared i.e. Australia and New Zealand. Finally, in relation to RQ3, we find there are differences between educational sectors, in that universities tend to adopt different marketing strategies in relation to ISR as opposed to secondary schools. These differences appear to be relatively consistent across countries.

\subsection{Discussion}

The type of education sector appears to be a factor in determining the most prevalent ISR marketing strategy for educational institutions. In both Australia and New Zealand, secondary schools and universities appear to have different prevailing ISR marketing strategies based on the education sector in which they operate. The prevailing ISR marketing strategy in both Australian and New Zealand universities was Operational Excellence whereas Customer Intimacy was the prevailing ISR marketing strategy in Australian and New Zealand secondary schools. The number of international students enrolled in Australian and New Zealand institutions may impact the prevailing ISR marketing strategy type. In 2010, the thirty nine universities in Australia and the eight universities in New Zealand had 233099 and 9678 international student enrolments respectively (AEI, 2010, Education Counts, 2010). In comparison the number of international students enrolled in the 1409 Australian and 48 
New Zealand secondary schools was 24235 and 16486 students respectively (AEI, 2010, Education Counts, 2010). On average each university in New Zealand enrolled over 2400 international students and the average enrolment at Australian universities was almost 6000 international students per institution. In comparison the average enrolment at New Zealand secondary schools was 48 international students whereas the average enrolment at Australian secondary schools was 17 international students. Given the number of international students enrolled at universities in Australia and New Zealand, perhaps institutions adopted a strategy such as Operational Excellence as this VDS focuses on cost minimisation and the standardisation of operations. In the case of secondary schools with much smaller international student enrolments perhaps the Customer Intimacy VDS was more applicable as this focuses on the development of relationships (Treacy and Wiersema, 1995).

Importantly, it was found that educational institutions do utilize a variety of ISR marketing strategies and can identify their current strategy using a value-based typology and a selftyping paragraph approach. Respondents found a value-based typology presented few difficulties, was meaningful and relevant for the operating environments of their institutions. This method appears useful for strategy identification in educational institutions.

At an institutional level, there exists some evidence of a relationship between the percentage of international students within the total student cohort and the ISR marketing strategy at that institution. Institutions in which the international student cohort comprised less than $10 \%$ of the total student cohort tended to self-select a customer intimacy ISR marketing strategy whereas institutions with larger international student populations tended to self-select operational excellence. The logic of this relationship seems rational in that, as the number of international students increase, so too the systems to manage the students must also increase 
in size and complexity. An alternate view is that the increased number of students reflects the institution's motivation in recruiting international students. It may be that a smaller percentage of international students encourages a focus on relationships (customer intimacy), whereas a larger percentage of international students encourages a focus on operations and systems (operational excellence). As such, the precise nature of this relationship is unclear and requires further investigation.

Additionally, a relationship appears to exist between institutional ISR years of experience and ISR marketing strategy. As institutions gain ISR experience there is a move from a focus on relationships (customer intimacy) to a focus on operations (operational excellence). For institutions with limited ISR recruitment experience (0-5 years), customer intimacy (35.8\%) and entrenched isolation (37.7\%) tend to be most prevalent. As institutional ISR experience increases (6-15 years), the prevalent ISR marketing strategies change to customer intimacy (37.8\%) and operational excellence (36.1\%). For institutions with considerable ISR experience (16+ years) operational excellence (31.1\%) and entrenched isolation $(30.1 \%)$ are the most prevalent strategies. The reason for the reappearance of entrenched isolation as an ISR marketing strategy requires further investigation. It may be that for institutions with limited ISR experience (0-5 years), ISR is a small and specialised activity and, as such, the ISR information is held by only a few people. Such a situation may enhance the likelihood of an entrenched isolation ISR marketing strategy being prevalent. In contrast, once an institution gains considerable ISR experience (16+ years) it may be that "empires" are established leading to an entrenched isolation strategy in order to protect the structure of the "empire". 


\section{Managerial Implications}

For education managers and international education practitioners some important managerial implications can be derived. The results clearly indicate there exists considerable variability in the ISR marketing strategies chosen by educational institutions. This indicates that when recruiting international students there is no single strategy that best fits all educational institutions. Furthermore, within education sectors, neither secondary schools nor universities were all categorised within one single strategy. However, there is some indication that the education sector plays some role in the adoption of an ISR marketing strategy. For example, across both Australia and New Zealand, operational excellence was found to be more prevalent for universities and customer Intimacy more prevalent in secondary schools. This does not necessarily indicate that institutions adopting this strategy type will be more successful when recruiting international students. They are simply more prevalent. As this is a cross-sectional study, the effect of strategic choice on institutional performance over time is not tested. Educational managers should make their own assessment regarding whether a specific ISR strategy is appropriate for their institution and operating environment. Potentially, the successful implementation of a less prevalent ISR strategy may provide an institution with a means to achieve a competitive advantage in a competitive market.

Although the antecedents of ISR strategy choice are beyond the scope of this paper, it is important to remind educational managers of the need to choose an ISR strategy based on the need of the customer (international students in this case) rather than the needs of the institution (Best, 2009). Choosing an ISR strategy based on international student needs would allow an institution to more effectively and efficiently target the desired international student segment. As such, the Entrenched Isolation ISR strategy would be of reduced benefit 
to an institution as it is based completely around organisational needs. In other words, educational institutions must move away from an internal focus, and should concentrate on adopting strategies that focus on the provision of value to external stakeholders

Once an institution has decided on an ISR strategy, education managers need to ensure that the institution itself actually portrays the features of that strategy. For example, an institution selecting an Operational Excellence ISR strategy needs to ensure that they are strongest in the efficiency and standardisation of their transactions and operations (features of the Operational Excellence strategy) rather than emphasising other features such as invention and development (Product Leadership) or solution development (Customer Intimacy). Failure to achieve an alignment of the selected ISR strategy features with the prevailing VDS in the institution will send mixed and confusing signals to the international student.

Additionally, education managers need to consider appropriate metrics for the measurement and evaluation of the selected ISR strategy. The metrics selected need to emphasise the features of the specific ISR marketing strategy. For example, evaluating the success of a Customer Intimacy ISR marketing strategy by the extent to which operations are standardised, optimised and efficient will not be particularly revealing as these are not features of the Customer Intimacy ISR marketing strategy.

For managers who seek to conceptualise an institution's ISR marketing strategy a valuebased typology is useful and the self-typing paragraph method is an efficient mechanism for strategy identification. As previously mentioned, the use of a value-based typology presented few difficulties for respondents and was meaningful and relevant for the operating environments of educational institutions. This then provides education managers with the 
necessary tool to identify the ISR marketing strategy in their institution and/or to implement strategic changes within the institution and then measure the effect of these changes on the ISR marketing strategy.

\section{Theoretical Implications}

The theoretical contribution of this research is noteworthy, in that it is not contextually bound within the scope of this study (i.e. educational ISR), but has significant implications for strategic marketing theory across a broad spectrum. The findings of this study resulted in the identification (phase 1) and validation (phase 2) of a fourth value discipline marketing strategy which extends the VDS typology developed by Treacy and Wiersema (1995). Labelled as entrenched isolation, this marketing strategy is highly likely to reside, not just within the walls of educational institutions, but also in many other organizational types. The very definition of the entrenched isolation marketing strategy highlights its close association with organizational structure. For example, entrenched isolation almost becomes a consequence of an organizational structure characterized by non-communicative individual departmental silos, operating with competing agendas, often within bureaucratic structures. Alternatively, it is suggested that this strategy might also be a consequence of organizational size where marketing specialists may well become involuntarily isolated within their particular area in smaller organizations. Whichever the case may be, it appears there is a close relationship between the entrenched isolation strategy and organizational structure and size. This being the case, it is expected that many organizations who exhibit similar size and structural characteristics as that just discussed might, in fact, demonstrate a similar strategic orientation as that described by entrenched isolation. On this basis, the extension of the VDS typology to a four-strategy typology, as a result of this study, provides a theoretical advancement that is will be useful in future strategy research and also managerial practice. 


\subsection{Limitations and Future Research}

The findings in this study are limited to two education sectors in Australia and New Zealand. In order to generalize the findings beyond this region, similar research needs to extend to a variety of different educational environments, countries and cultures. Furthermore, the use of the Value Discipline typology, expanded Value Discipline typology, and the self-typing paragraph method, used in this study, may well provide a valid framework for future educational research in the areas of domestic student recruitment, course development and facilities development. Moreover, these mechanisms can also be useful in many other marketing contexts.

Specifically, further research should seek to identify the factors that have contributed to the ISR marketing strategy choices made by educational institutions. While the research contained herein provides a conceptualisation of existing ISR marketing strategies in educational institutions, the decisions that led to the implementation of the respective strategies remain unexplored. Additionally, the extent of institutional performance success based on strategic choices is also worthy of future investigation.

\subsection{Conclusion}

Maintaining sustainability presents many challenges to organizations in today's competitive environment and educational institutions are not exempt from such marketplace pressure. While marketing research in the context of educational institutions continues to grow, little is known about the strategic choices associated with international student recruitment (ISR), an important activity which, increasingly, has significant influence on the longevity and 
prosperity of education institutions in many countries. This research has identified and empirically validated a relevant strategy framework for use in furthering our knowledge in relation to strategic marketing approaches of ISR departments in educational institutions. In doing so, strategic marketing theory, in general, has been extended and, in particular, significant advancement of our knowledge of ISR strategies is gained. Future research will also benefit from the findings of this study which provide a solid platform for further investigation in this important research area. 


\section{REFERENCES}

AEI (2010), "International Student Data 2010 ", available at: http://www.aei.gov.au/research/International-StudentData/Pages/InternationalStudentData2010.aspx (accessed 3 November 2011).

Bednall, D.H.B. and Valos, M.J. (2005), "Marketing research performance and strategy", International Journal of Productivity and Performance Management, Vol. 54 No. 5/6, pp. 438-450.

Bendoly E., Rosenzweig, E.D. and Stratman, J.K. (2009) "The efficient use of enterprise information for strategic advantage: A data envelopment analysis", Journal of Operations Management, Vol. 27 No. 4, pp. 310-323.

Bennett, J.C. (2004), The Anglosphere Challenge: Why English-Speaking Nations Will Lead the Way in the Twenty-First Century, Rowman \& Littlefield, Lanham, MA.

Best R.J. (2009) Market-based management: Strategies for growing customer value and profitability, Prentice Hall, Upper Saddle River, NJ.

Christopher M. (1996) "From brand values to customer value", Journal of Marketing Practice, Vol. 2 No. 1, pp. 55-66.

Chung E. and McLarney, C. (2000) "The classroom as a service encounter: Suggestions for value creation," Journal of Management Education, Vol. 24 No. 4, pp. 484-500.

Conant, J.S., Mokwa, M.P. and Varadarajan, P.R. (1990), "Strategic types, distinctive marketing competencies and organizational performance: A multiple measures-based study", Strategic Management Journal, Vol. 11 No. 5, pp. 365-383.

Dannhauser Z. and Roodt, G. (2001) "Value disciplines: Measuring customer preferences", Journal of Industrial Psychology, Vol. 27 No. 1, pp. 8-16.

Decaudin, J. and Lacoste, D. (2010), "Are services advertised differently? An empirical examination”, Journal of Services Marketing, Vol. 24 No. 7, pp. 546-553.

Demirkan, H., Kauffman, R.J., Vayghan, J.A., Fill, H. and Karagianni, D. (2008), “Serviceoriented technology and management: Perspectives on research and practice for the coming decade", Electronic Commerce Research and Applications, Vol. 7 No. 4, pp. 356-376.

Education Counts (2010), "International Education", available at: http://www.educationcounts.govt.nz/statistics/international_education (accessed 27 January 2011).

Godlevskaja, O., van Iwaarden, J. and van der Wiele, T. (2011), "Moving from product-based to service based business strategies", International Journal of Quality \& Reliability Management, Vol. 28 No. 1, pp. 62-94.

Gronroos C. (1991) "The marketing strategy continuum: Towards a marketing concept for the 1990s", Management Decision, Vol. 29 No. 1, pp. 7-13.

Hambrick, D.C. (1980), "Operationalizing the concept of business-level strategy in research", Academy of Management Review, Vol. 5 No. 4, pp. 567-575.

Harvey, J.A. and Busher, H. (1996), "Marketing schools and consumer choice", International Journal of Educational Management, Vol. 10 No. 4, pp. 26-32.

Hemsley-Brown, J. and Oplatka, I. (2006), "Universities in a competitive global marketplace: A systematic review of the literature on higher education marketing", International Journal of Public Sector Management, Vol. 19 No. 4, pp. 316-338.

Hemsley-Brown, J. and Oplatka, I. (2010), "Market orientation in universities: A comparative study of two national higher education systems", International Journal of Educational Management, Vol. 24 No. 3, pp. 204-220. 
Hooley G. and Greenley, G. (2005) "The resource underpinnings of competitive positions", Journal of Strategic Marketing, Vol. 13 No. 2, pp. 93-116.

Hooley, G.J., Lynch, J.E. and Jobber, D. (1992), "Generic marketing strategies", International Journal of Research in Marketing, Vol. 9 No. 1, pp. 75-89.

Howitt D. and Cramer, D. (2010) Introduction to Research Methods in Psychology, PrenticeHall, Harlow.

Huber, G.P. and Power, D. (1985), "Retrospective reports of strategic-level managers: Guidelines for increasing their accuracy”, Strategic Management Journal, Vol. 6 No. 2, pp. 171-180.

Ilieva, J., Baron, S. and Healey, N.M. (2002), "Online surveys in marketing research: Pros and cons", International Journal of Market Research, Vol. 44 No. 3, pp. 361-382.

James, W.L. and Hatten, K.J. (1995), "Further evidence on the validity of the self typing paragraph approach: Miles and Snow strategic archetypes in banking”, Strategic Management Journal, Vol. 16 No. 2, pp. 161-168.

Kenyon, P. and Koshy, P. (2003), The Economic Benefits to Australia from International Education: Final Report, The Australian Government International Education Network, Canberra.

Kotler, P. and Murphy, P.E. (1981), "Strategic planning for higher education", The Journal of Higher Education, Vol. 52 No. 5, pp. 470-489.

Langerak F. and Verhoef, P.C. (2008) "Strategically embedding CRM", Business Strategy Review, Vol. 14 No. 4, pp. 73-80.

Lovelock, C.H. (1983), "Classifying services to gain strategic marketing insights", Journal of Marketing, Vol. 47 No. 3, pp. 9-20.

Lusch, R.F. and Vargo, S.L. (2008), "The Service-Dominant Mindset”, in Hefley, B. and Murphy, W. (Eds.) Service Science, Management and Engineering: Education for the 21 st Century, Springer, New York, NY.

Maringe, F. (2004), "Vice chancellor's perceptions of university marketing: A view from universities in a developing country", Higher Education Review, Vol. 36 No. 2, pp. 53-68.

Maringe, F. and Foskett, N.H. (2002), "Marketing university education: The South African experience", Higher Education Review, Vol. 34 No. 3, pp. 35-51.

Mazzarol, T. and Hosie, P. (1996), "Exporting Australian higher education: Future strategies in a maturing market", Quality Assurance in Education, Vol. 4 No. 1, pp. 37-50.

Mazzarol, T. and Soutar, G.N. (2008), "Strategy matters: Strategic positioning and performance in the education sector", International Journal of Nonprofit and Voluntary Sector Marketing, Vol. 13 No. 2, pp. 141-151.

Micheels E.T. and Gow, H.R. (2009) "Do market oriented firms demonstrate clarity in their value discipline? Evidence from Illinois beef producers", International Food and Agribusiness Management Review, Vol. 12 No. 3, pp. 127-152.

Miles, R.E. and Snow, C.S. (1978), Organizational Strategy, Structure and Process, Prentice Hall, New York.

Morgan, R.E., Strong, C. and McGuinness, T. (2003), "Product-market positioning and prospector strategy: An analysis of strategic patterns from the resource based perspective", European Journal of Marketing, Vol. 37 No. 10, pp. 1409-1439.

Naidoo, V. (2010), "From ivory towers to international business: Are universities export ready in their recruitment of international students?", Journal of Studies in International Education, Vol. 14 No. 1, pp. 5-28.

Naude, P. and Ivy, J. (1999), "The marketing strategies of universities in the United Kingdom”, The International Journal of Educational Management, Vol. 13 No. 3, pp. 126-134. 
OECD (2010) PISA 2009 Results: What Students Know and Can Do - Student Performance in Reading, Mathematics and Science. OECD, Paris.

Ostrom, A.L., Bitner, M.J., Brown, S.W., Burkhard, K.A, Goul, M., Smith-Daniels, V., Demirkan, H. and Rabinovich, E. (2010), "Moving forward and making a difference: Research priorities for the science of service", Journal of Service Research, Vol. 13 No. 1, pp. 4-36.

Porter, M.E. (1980), Competitive Strategy: Techniques for Analysing Industries and Competitors, Free Press, New York.

Porter, M.E. (1985), Competitive Advantage: Creating and Sustaining Superior Performance, Free Press, New York.

Porter, M.E. (1998) The Competitive Advantage of Nations: With a New Introduction, MacMillan, New York.

Ross, M., Heaney, J. and Cooper, M (2007), "Institutional and managerial factors affecting international student recruitment", International Journal of Educational Management, Vol. 21 No. 7, pp. 593-605.

Scholey C. (2005) "Strategy maps: A step-by-step guide to measuring, managing and communicating", Journal of Business Strategy, Vol. 26 No. 3, pp. 12-19.

Schuler R.S. (1996) "Market-focused management: Human resource management implications", Journal of Market - Focused Management, Vol. 1 No. 1, pp. 13-29.

Shortell, S.M. and Zajac, E.J. (1990), "Perceptual and archival measures of Miles and Snow's strategic types: A comprehensive assessment of reliability and validity", Academy of Management Journal, Vol. 33 No. 4, pp. 817-832.

Slater, S.F. and Narver, J.C. (1993), "Product-market strategy and performance: An analysis of the Miles and Snow strategy types", European Journal of Marketing, Vol. 27 No. 10, pp. 33-51.

Slater, S.F. and Olson, E.M. (2001), "Marketing's contribution to the implementation of business strategy: An empirical analysis", Strategic Management Journal, Vol. 22 No. 11, pp. 1055-1067.

Slater, S.F., Olson, E.M. and Hult, G.T.M. (2006), "The moderating influence of strategic orientation on the strategy formation capability-performance relationship", Strategic Management Journal, Vol. 27 No. 12, p. 1221-1231.

Thornhill S. and White, R.E. (2007) "Strategic purity: A multi-industry evaluation of pure vs. hybrid business strategies", Strategic Management Journal, Vol. 28 No. 5, pp. 553561.

Treacy, M. and Wiersema, F. (1995), The Discipline of Market Leaders: Choose Your Customers, NarrowYour Focus, Dominate Your Market, Addison-Wesley, Reading, MA.

UNESCO (2009), Global Education Digest 2009: Comparing Education Statistics Across the World. UNESCO Institute for Statistics, Montreal.

Walker, O.C. Jr and Ruekert, R.W. (1987), "Marketing's role in the implementation of business strategies: A critical review and conceptual framework", Journal of Marketing, Vol. 15 No. 3, pp. 15-33.

Wiig K.M. (1997) "Knowledge management: Where did it come from and where will it go?", Expert Systems With Applications, Vol. 13 No. 1, pp. 1-14.

Wijaya S., Spruit, M., Scheper, W. and Versendaal, J. (2011) "Web 2.0-based webstrategies for three different types of organizations", Computers in Human Behavior, Vol. 27 No. 4, pp. 1399-1407.

Zack M., McKeen, J. and Singh, S. (2009) "Knowledge management and organizational performance: An exploratory analysis", Journal of Knowledge Management, Vol. 13 No. 6, pp. 409. 
Zahay, D. and Griffin, A. (2010), "Marketing strategy selection, marketing metrics, and firm performance", Journal of Business \& Industrial Marketing, Vol. 25 No. 2, pp. 84-93.

Zeithaml V.A., Parasuraman, A. and Berry, L.L. (1985) "Problems and strategies in services marketing," Journal of Marketing, Vol. 49 No. 2, pp. 33-46.

(c) Emerald Group Publishing Limited

This is a pre-print of a paper and is subject to change before publication. This pre-print is made available with the understanding that it will not be reproduced or stored in a retrieval system without the permission of Emerald Group Publishing Limited. 


\section{Table 1: Qualitative Results Pertaining to Emergent Strategy: Entrenched Isolation}

Marketing strategies are developed within the International Education Office and contained within the department. Specific responsibilities for individuals.

Influence from outside the International Office is actively resisted.

Decision making is kept within the department - not delegated.

Knowledge is guarded by a few (in this case "we" refers to two people). Protection of knowledge.

All international activity resides in one location - creation of a silo - international office.

Resistance to change in the International Office

Actively maintaining control over a period of years. Ownership

Development and maintenance of a system of entrenched isolation
"Our marketing strategies have historically been developed by having people who have country specific expertise and responsibilities. They develop networks and a lot of knowledge of regulatory environments and the marketing and student demand. Our marketing strategies haven't been reviewed."

University

"There are some people [from outside the international office] who think we should go to operational excellence . . . . but we are not going to let them do it."

University

"I wouldn't say that we have a culture that encourages delegation of decision-making."

University

"We review our existing markets - we have been doing this for a while so we know who to contact and how to keep the marketing program rolling along. Much of the strategy is in our heads because we have been doing this for a while."

School

"We are the international part of the university.

The aim is that all international activity will sit here. It's very clear to the university that this is where all that resides."

University

"It is hard for some people to give up some things they have developed."

University

"I've been here for ten years so I've been here since there was nothing. In my institution I have had a lot of autonomy. I've been able to structure the job in a way that I have felt has suited me. I've found that people who get frustrated in the job and find it irritating are people who haven't got very much control over how it is going and what's happening".

School

"[We have] an organizational structure that encourages operations where you have an international education office which does marketing on behalf of all schools. [O]ur principals are not allowed to go overseas and market and everything is done through this office. They [principals] are in charge of the education system in their school. They are the business manager and they are the leader of their operation and as far as I $m$ concerned that is their major function". 


\section{Table 2: ISR Marketing Strategy Descriptors}

\section{Strategy Descriptor}

Operational At this institution there is a tendency to optimise procedures to excellence minimise costs. Our organizational structure encourages standardised operations. Our systems are integrated with an emphasis on reliable transactions. Our culture rewards efficiency.

Product

leadership

At this institution there is a tendency towards invention and development. Our organizational structure encourages entrepreneurialism. Our systems are results driven. Our culture encourages imagination.

Customer intimacy

Entrenched isolation
At this institution there is a tendency towards solution development. Our organizational structure encourages delegating decision-making. Our systems are focussed on creating results. Our culture is focussed on relationships.

At this institution there is a tendency to develop secure departments each with their own knowledge base. Our organizational structure encourages retention of information within each department. Our systems are focussed on individual performance. Our culture encourages individuals to develop competencies in specific areas.

Source: Adapted from Treacy and Wiersema (1995) and developed for this study 
Table 3: Sample by Institution Type and Country

\section{Australia New Zealand Total}

(sector)

$\begin{array}{lccc}\text { Secondary Schools } & 143 & 137 & 280 \\ \text { Universities } & 159 & 65 & 224 \\ \text { Total (country) } & 302 & 202 & 504\end{array}$

(C) Emerald Group Publishing Limited

This is a pre-print of a paper and is subject to change before publication. This pre-print is made available with the understanding that it will not be reproduced or stored in a retrieval system without the permission of Emerald Group Publishing Limited. 
Table 4: Results of Self-Classification

\begin{tabular}{|c|c|c|c|c|}
\hline \multirow[b]{2}{*}{ Strategy } & \multirow{2}{*}{\multicolumn{2}{|c|}{$\begin{array}{c}\text { Australia } \\
\text { School }\end{array}$}} & \multicolumn{2}{|c|}{ New Zealand } \\
\hline & & & University & School \\
\hline $\begin{array}{l}\text { Operational } \\
\text { Excellence }\end{array}$ & $41.5 \%$ & $21.0 \%$ & $61.5 \%$ & $27.0 \%$ \\
\hline $\begin{array}{l}\text { Product } \\
\text { Leadership }\end{array}$ & $19.5 \%$ & $17.4 \%$ & $1.5 \%$ & $10.2 \%$ \\
\hline $\begin{array}{l}\text { Customer } \\
\text { Intimacy }\end{array}$ & $19.5 \%$ & $35.0 \%$ & $17.0 \%$ & $48.2 \%$ \\
\hline $\begin{array}{l}\text { Entrenched } \\
\text { Isolation }\end{array}$ & $19.5 \%$ & $26.6 \%$ & $20.0 \%$ & $14.6 \%$ \\
\hline Total & $100.0 \%$ & $100.0 \%$ & $100.0 \%$ & $100.0 \%$ \\
\hline
\end{tabular}

(C) Emerald Group Publishing Limited

This is a pre-print of a paper and is subject to change before publication. This pre-print is made available with the understanding that it will not be reproduced or stored in a retrieval system without the permission of Emerald Group Publishing Limited. 